\title{
Mechanical Analysis of Fiber Reinforced Adobe
}

\author{
Omar Khtou $^{1, *}$, Issam Aalil ${ }^{1}$, Mohamed Aboussaleh ${ }^{1}$, Fatima Zohra EL Wardi ${ }^{2}$ \\ ${ }^{1}$ Laboratory of Sciences and Engineering, ENSAM, Moulay Ismail University, Meknes, 50000, Morocco \\ ${ }^{2}$ EMDD_CERNE2D, Mohammed V University, EST, Sale, 11000, Morocco
}

Received July 11, 2021; Revised September 22, 2021; Accepted October 17, 2021

\section{Cite This Paper in the following Citation Styles}

(a): [1] Omar Khtou, Issam Aalil, Mohamed Aboussaleh, Fatima Zohra EL Wardi , "Mechanical Analysis of Fiber Reinforced Adobe," Civil Engineering and Architecture, Vol. 9, No. 7, pp. 2160-2168, 2021. DOI: 10.13189/cea.2021.090705.

(b): Omar Khtou, Issam Aalil, Mohamed Aboussaleh, Fatima Zohra EL Wardi (2021). Mechanical Analysis of Fiber Reinforced Adobe. Civil Engineering and Architecture, 9(7), 2160-2168. DOI: 10.13189/cea.2021.090705.

Copyright $@ 2021$ by authors, all rights reserved. Authors agree that this article remains permanently open access under the terms of the Creative Commons Attribution License 4.0 International License

\begin{abstract}
The south-east of the kingdom of Morocco, including the Tinejdad region at the south-east, has a remarkable earthen architecture. It is built by combining two techniques, that of rammed earth and that of adobe. This work is carried out with the aim of preserving and developing this ancestral know-how. The study is initially a characterization of the soil used for earthen construction in the region; the grain size and plasticity of the soil showed that it was not very clayey and moderately plastic (clayey sand) and it was suitable for earthen construction. The characterization also concerned the fibers traditionally used, namely wheat straw and barley straw. Secondly, the study focuses on the influence of different fibers, those mentioned above as well as sawdust and the crushing of barley straw on the mechanical characteristics of adobe in relation to its compressive strength and bending strength. Several fiber mass ratios were studied, and an improvement in compressive strength and bending strength was observed for the different fibers. The fibers have also provided a great improvement in the ductility of the adobe and a decrease in the modulus of elasticity. The optimal mass ratio of the fibers was $2 \%$ for the different fibers studied.
\end{abstract}

Keywords Adobe, Ductility, Elasticity, Fiber Reinforcement, Raw Earth, Straw, Strength

\section{Introduction}

For thousands of years, construction has been done exclusively with local materials; if we take the example of the Great Wall of China, we can see that it adapts throughout its course to the nature of the ground on which it is built. Thus, we find parts built of stone on the rock, earth on the earth and sometimes even sand in some desert parts. Given the size of the territory crossed by this building, it was built using local materials in order to limit the transport of the extraction area to that of the construction site. Exploiting local materials to build your home is a universal behavior. And often, earth is the only material available. Studies estimate that at least $30 \%$ of the world's population lives in earthen buildings and $17 \%$ of buildings inscribed on UNESCO's World Heritage List are earthen architectural works [1].

For more than a thousand years, raw earth has been a material of choice for construction in the oases of south-eastern Morocco. These oases are known by the presence of various large fortresses known as ksar (or ksour in plural). These constructions represent an architectural part of the national heritage and also of the UNESCO world heritage such as the ksar ait Benhaddou (Figure 1). El Khorbat ksar, located near Tinejdad city, is an example of vernacular architecture tackled in many studies [2] (Figure 2). These constructions were made using two main techniques: rammed earth and adobe. The rammed earth technique consists of tamping damp earth in a formwork. The earth is poured into a formwork in layers. Adobe is a mud brick shaped by hand or in a wooden mold in a plastic state and air-dried. This is often reinforced with straw fibers.

Earth construction provides thermal compliance in an arid climate, which is very hot in summer and cold in winter. It reduces heating and cooling energy requirements through heat storage capacity of the rammed 
earth materials, which is beneficial to the environment. In addition, raw earth is a material with low gray energy and its operation meets environmental requirements. However, the use of this material faces many obstacles as the non-uniformity unlike cement concrete: the material changes enormously from one region to another and from one deposit to another.

This work focuses on raw materials used in the city of Tinejdad, located in a south-eastern oasis of Morocco, to make reinforced adobe bricks for local and ecological construction. The reinforcement of earth is mainly made of fibers of wheat or barley straw. Our objective was to characterize first the available earth in the ksar of Gardmit, belonging to the city of Tinejdad, and the local vegetal fibers and then to determine an optimal reinforcement for the adobe.

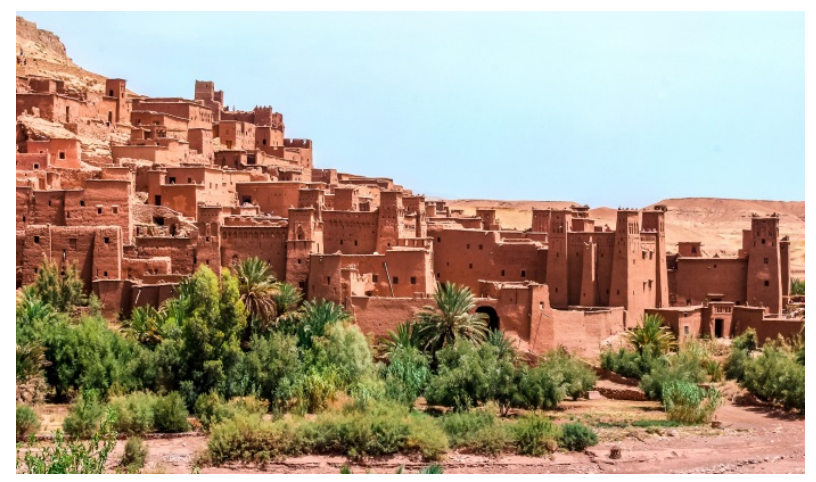

Figure 1. Ksar Ait Benhaddou

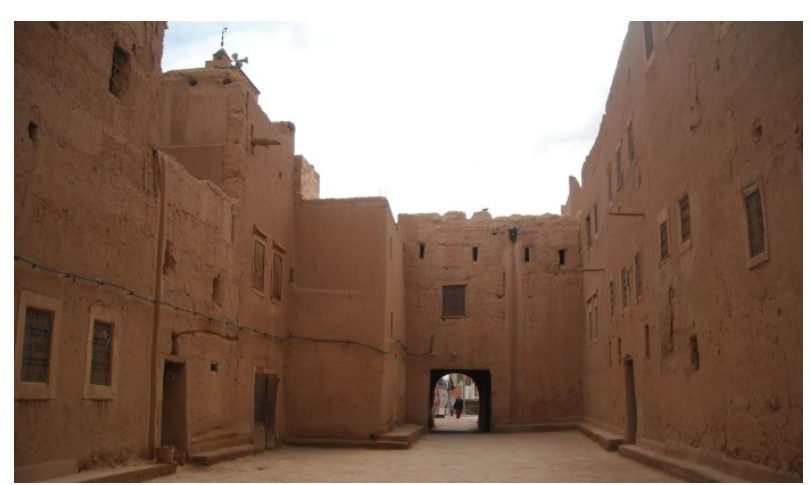

Figure 2. The raw earth construction in Tinejdad oasis

\section{Materials and Testing Methods}

\subsection{Raw Materials}

The raw earth, also known as earth concrete in analogy with cement concrete, consists of gravel, sand and fine elements that are clay and silt acting as cement. The soil used for this study was extracted in the ksar of Gardmit attached to the city of Tinejdad, from a depth of $10 \mathrm{~cm}$ to avoid the organic soil.

The vegetal fibers in this study are wheat straw, barley straw and a sawdust. The used straws were extracted locally from the same region of Tinejdad. The used sawdust came from the waste of carpentry workshops using cedar wood and all fibers were dried before use.

\subsubsection{Soil}

The soil was characterized using the following methods:

The particle size analysis: It was carried out in two stages: by sieving according to the standard NF P 94-056 [3], then by sedimentation following the standard NF P 94-057 [4], on the fraction less than $80 \mu \mathrm{m}$. The particle size analysis, therefore, determines the different proportions of the different grain sizes highlighting the percentages of clays, silt, sand and gravel.

The plasticity index (PI) was measured on the fraction of soils between 0 and $400 \mu \mathrm{m}$. The (PI) was calculated from the liquidity limit WL and the limit of plasticity WP, determined following the NF P94-051 standard [5], using the equation:

$$
\mathrm{PI}=\mathrm{WL}-\mathrm{WP}
$$

The methylene blue (BV) test was carried according to the NF P94-068 standard [6]. It characterizes the specific surface of a soil. It turns out to be an indicator of the activity of the clays presence [7].

\subsubsection{Fibers}

In this study, bulk densities of the fibers are determined in the same technique used for sand and gravel. More particularly, this was done by filling a standard container without compacting.

The mechanical proprieties of wheat and barley straw were determined by using the bending test. To do this, 10 $\mathrm{cm}$ long fibers were used to determine the resistance in traction. In order to avoid damage to the fibers on the ends, the whole straw was grouped together with $3 \mathrm{~cm}$ long adhesive tape from each end. The studied straw is, therefore, $4 \mathrm{~cm}$ long, which corresponds to the central part. It is at this level that the calculation of the deformation is carried out. The loading speed was fixed at $1 \mathrm{~mm} /$ minute.

\subsection{Test Plan and Samples Preparation}

\subsubsection{Samples}

It is worth noting that the bricks whose dimensions were: $4 \times 4 \times 16 \mathrm{~cm}^{3}$ are made, three of each specimen, by mixing the raw earth with the different fibers: wheat straw, barley straw, crushed barley straw and sawdust, with different mass rates, as described in the Table 1 . The mixture was made with a quantity of water giving the soil a water content equal to its plastic limit.

The fiber mass rates to study were chosen $0.5 \%, 1 \%$, $1.5 \%, 2.5 \%$, $3 \%$ and $3.5 \%$ and the length of the straw used was $4 \mathrm{~cm}$, based on previous studies [8]. The fresh samples are then left in the prismatic mold for a period of 
3 days before demolding. The minimum duration before the drying tests required is 28 days [8]. The tests were carried out after 6 months.

\subsubsection{Adobe sample tests}

In order to determine the influence of the reinforcement of the adobe with the different types of fibers and their ratio on the adobe strength, two tests were performed: the three-point bending test and the unconfined compression test. The bending strength is determined by the three-point test on the $4 \times 4 \times 16 \mathrm{~cm}^{3}$. The test piece is supported by two supports spaced $100 \mathrm{~mm}$ apart and loaded in its center. The test loading speed was $300 \mathrm{~N} / \mathrm{min}$ [9]. In the compression test, the specimen is subjected to an increasing load until failure. The press was force-driven, with an imposed loading speed of $3 \mathrm{kN} / \mathrm{min}$ [9]. The stress-strain curve was obtained using a $20 \mathrm{~mm}$ displacement transducer.

\section{Results and Discussion}

\subsection{Materials characteristics}

\subsubsection{Soil}

Tables 2 and 3 show the characteristics of the soil used, the definitions of the different fractions of the grain size are given in accordance with the standard NF P18-560 [10]. The results of the particle size analysis indicate that the soil contains about $13 \%$ of gravel, $63 \%$ of sand, $12 \%$ of silt and $12 \%$ of clay. The Atterberg limits are $20 \%$ for the liquid limit and $7.5 \%$ for the plasticity index, respectively. The soil used is classified as clayey sand according to the soil classifications LPC and USCS [11,12]. This soil satisfies the Moroccan earthquake resistant earth construction regulation requirements for adobe, except for the liquidity limit which is below the minimum threshold of $25 \%$ [13].

\subsubsection{Fibers}

The bulk densities of the fibers are summarized in Table 4. They are in the same range of the different straws reported in the relevant literature [14]. The bulk density of wheat straw is greater than that of barley straw. This difference is due to the fact that barley straw is of larger diameter, it has a greater void index. Once the barely straw is crushed, its bulk density increased by more than $50 \%$.

Table 1. The different test specimens

\begin{tabular}{|c|c|c|c|c|c|}
\hline Specimen & Fiber & $\begin{array}{c}\text { Mass percentage of } \\
\text { fiber }\end{array}$ & Specimen & Fiber & $\begin{array}{c}\text { Mass percentage of } \\
\text { fiber }\end{array}$ \\
\hline $\mathrm{R}$ & None & 0 & CB0.5 & Crushed barley straw & 0.5 \\
\hline W0.5 & Wheat straw & 0.5 & CB1 & Crushed barley straw & 1 \\
\hline W1 & Wheat straw & 1 & CB1.5 & Crushed barley straw & 1.5 \\
\hline W1.5 & Wheat straw & 1.5 & CB2 & Crushed barley straw & 2 \\
\hline W2 & Wheat straw & 2 & CB2.5 & Crushed barley straw & 2.5 \\
\hline W2.5 & Wheat straw & 2.5 & CB3 & Crushed barley straw & 3 \\
\hline W3 & Wheat straw & 3 & CB3.5 & Crushed barley straw & 3.5 \\
\hline W3.5 & Wheat straw & 3.5 & D0.5 & Sawdust & 0.5 \\
\hline B0.5 & Barley straw & 0.5 & D1 & Sawdust & 1 \\
\hline B1 & Barley straw & 1 & D1.5 & Sawdust & 1.5 \\
\hline B1.5 & Barley straw & 1.5 & D2 & Sawdust & 2 \\
\hline B2 & Barley straw & 2 & D2.5 & Sawdust & 2.5 \\
\hline B2.5 & Barley straw & 2.5 & D3 & Sawdust & 3 \\
\hline B3 & Barley straw & 3 & D3.5 & Sawdust & 3.5 \\
\hline B3.5 & Barley straw & 3.5 & & & \\
\hline
\end{tabular}


As shown in Figure 3, the behavior of wheat straw and barley straw was quite similar. The maximum strength is $38 \mathrm{MPa}$ for barley straw and $31 \mathrm{MPa}$ for wheat straw. The barley straw showed a slightly greater ductility than that of wheat straw. The maximum strength is reached for a strain of $1.78 \%$ for barley straw whereas it was $1.70 \%$ for wheat straw.

The fluctuations at the level of the curve were due to the fact that the breaking of the straw did not occur at the same time on all the fibers, which were broken off one by one. As it can be seen, the first part of the curve is linear, and it shows a Young's modulus of $1.78 \mathrm{GPa}$ for wheat straw and 2.15 GPa for barley straw.

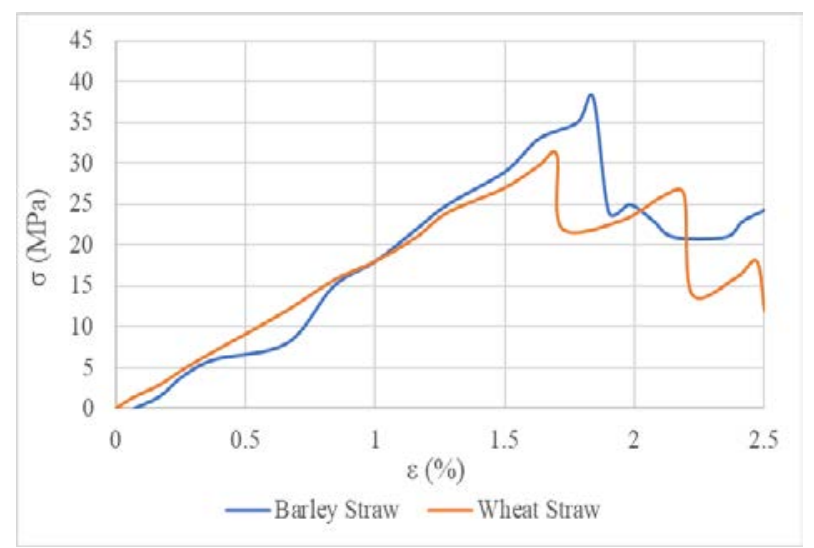

Figure 3. Stress-Strain curves of barley and wheat straw
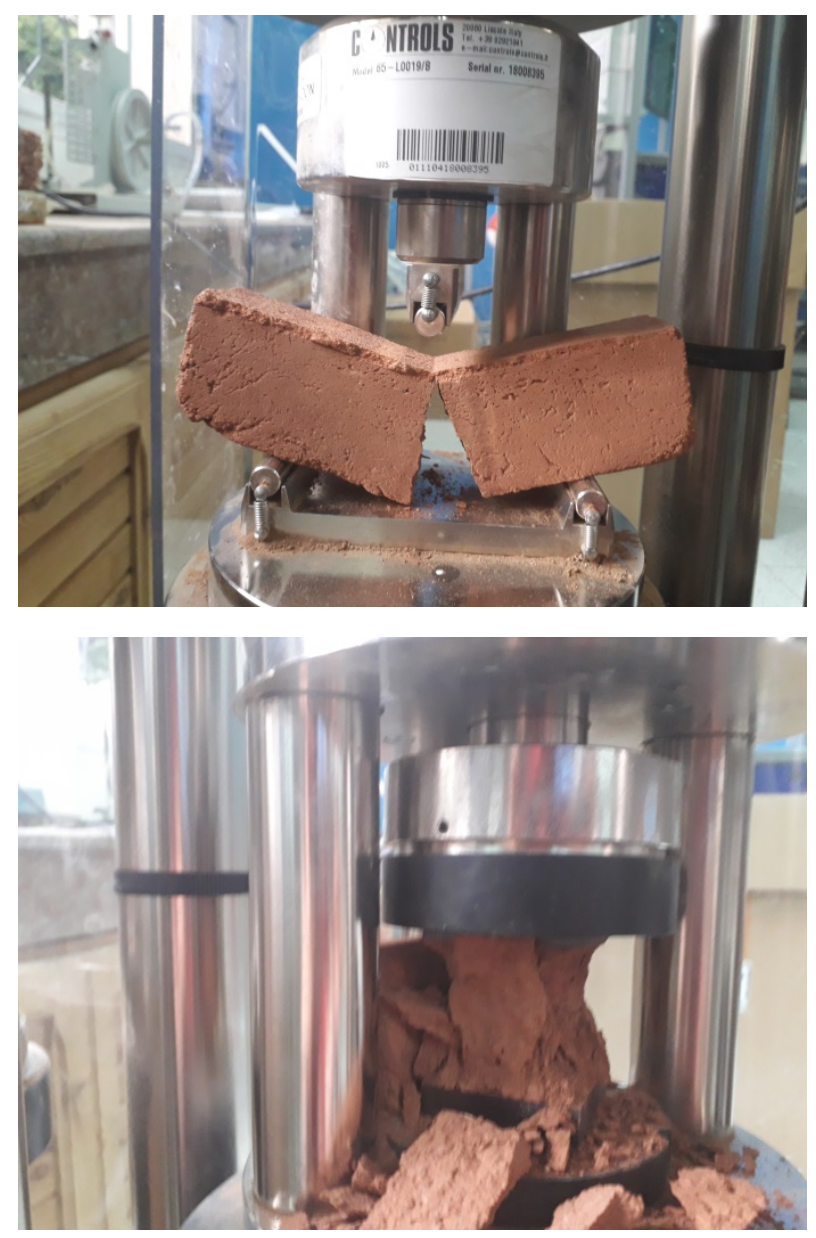

Figure 4. The bending and compression tests

Table 2. Raw earth granulometry

\begin{tabular}{|c|c|c|c|c|c|c|}
\hline $\begin{array}{c}\text { Pebbles } \\
(200 \mathrm{~mm}-20 \mathrm{~mm})\end{array}$ & $\begin{array}{c}\text { Gravel } \\
(20 \mathrm{~mm}-2 \mathrm{~mm})\end{array}$ & $\begin{array}{c}\text { Coarse sands } \\
(2 \mathrm{~mm}-0.2 \mathrm{~mm})\end{array}$ & $\begin{array}{c}\text { Fine sands } \\
(0.2 \mathrm{~mm}-0.06 \mathrm{~mm})\end{array}$ & $\begin{array}{c}\text { Silt } \\
(0.06 \mathrm{~mm}-0.02 \mathrm{~mm})\end{array}$ & $\begin{array}{c}\text { Fine Silt } \\
(0.02 \mathrm{~mm}-0.002 \mathrm{~mm})\end{array}$ & $\begin{array}{c}\text { Clay } \\
(<0.002 \mathrm{~mm})\end{array}$ \\
\hline $0 \%$ & $13 \%$ & $30 \%$ & $33 \%$ & $5 \%$ & $7 \%$ & $12 \%$ \\
\hline
\end{tabular}

Table 3. Raw earth characteristics

\begin{tabular}{|c|c|c|c|c|}
\hline Fine content (\%) & Liquidity limit (\%) & Plasticity limit (\%) & Plasticity Index (\%) & Methylene Blue Value \\
\hline 24 & 20.2 & 12.7 & 7.5 & 2.75 \\
\hline
\end{tabular}

Table 4. Fibers apparent densities

\begin{tabular}{|c|c|c|c|c|}
\hline Fiber & Barley straw & Wheat straw & Crushed barley Straw & Sawdust \\
\hline Apparent density $\left(\mathrm{kg} / \mathrm{m}^{3}\right)$ & 107 & 123 & 150 & 450 \\
\hline
\end{tabular}




\subsection{Mechanical Characterization of Adobe Samples}

\subsubsection{Simple Compression Test}

The mechanical characterization of the adobe samples was carried to compare the mechanical behavior of different mixes (Figure 4). Figure 5 shows the stress strain curve of the adobe without fibers, considered as reference R. Compared to the recommendations of different standards [15-17], the present adobe satisfies the required compressive strength. The most demanding standard, being the New Mexico code, imposes a minimum compressive strength of 2.07 $\mathrm{MPa}$ [17].

Figures 6, 7, 8 show the average stress-strain curves of the test pieces reinforced with $1 \%, 2 \%$ and $3 \%$ of the different fibers, accompanied by the reference curve R.

On the stress strain curves, there is a first domain where the slope of the stress-strain curve reaches its maximum.
This corresponds to an approximate deformation of $0.8 \%$ for the reference specimen, between $15 \%$ and $1.7 \%$ for a fiber content of $1 \%$, a strain between $1.9 \%$ and $2.2 \%$ for a fiber content of $2 \%$ and a strain between $1.7 \%$ and $2.4 \%$ for a fiber content of $3 \%$. A second zone corresponds to an advanced plasticization of the material. For the reference specimen $\mathrm{R}$, the stress-strain slope smoothes continuously, whereas for the other specimens there are fluctuations before reaching the maximum resistance. These fluctuations are due to the presence of fibers which represent inhomogeneities in the material. A third domain, called post-peak resistance domain, which corresponds to the behavior of the material after the onset of the break described above; the rupture is of the "ductile" type for the fiber-reinforced soil, which highlights, among other things, the effect of fibers which maintain a certain post-fracture cohesion.

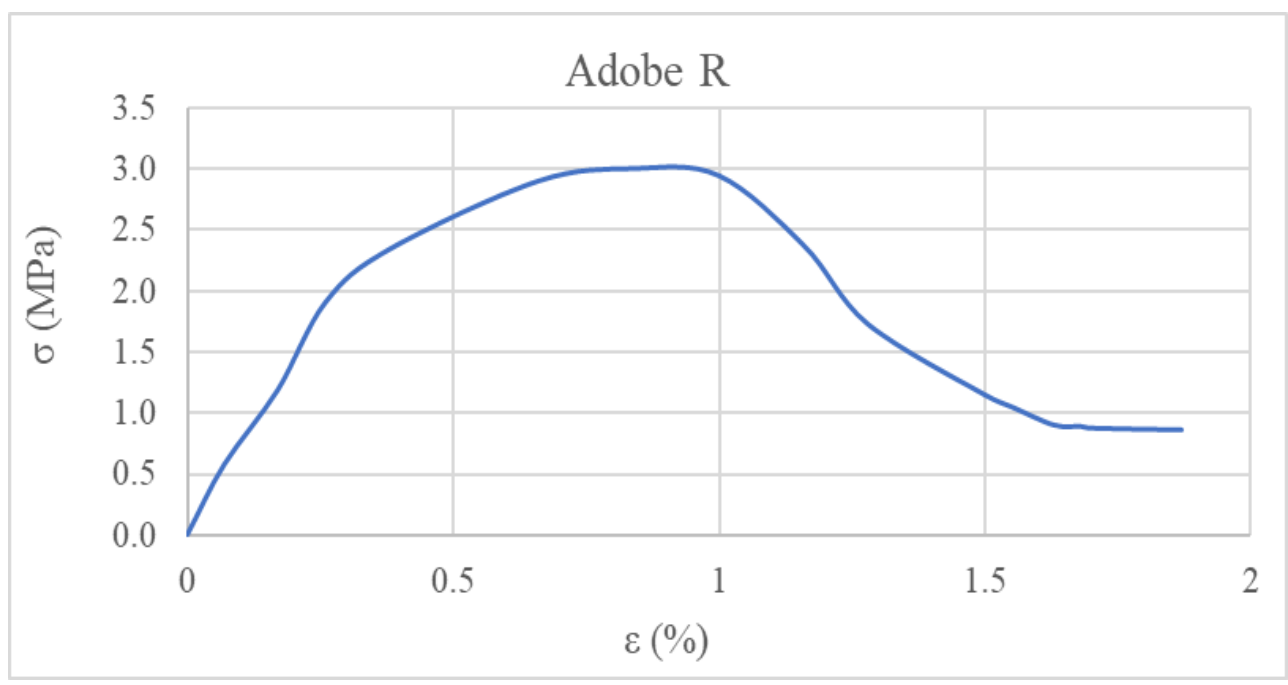

Figure 5. Stress-Strain curves of the reference adobe

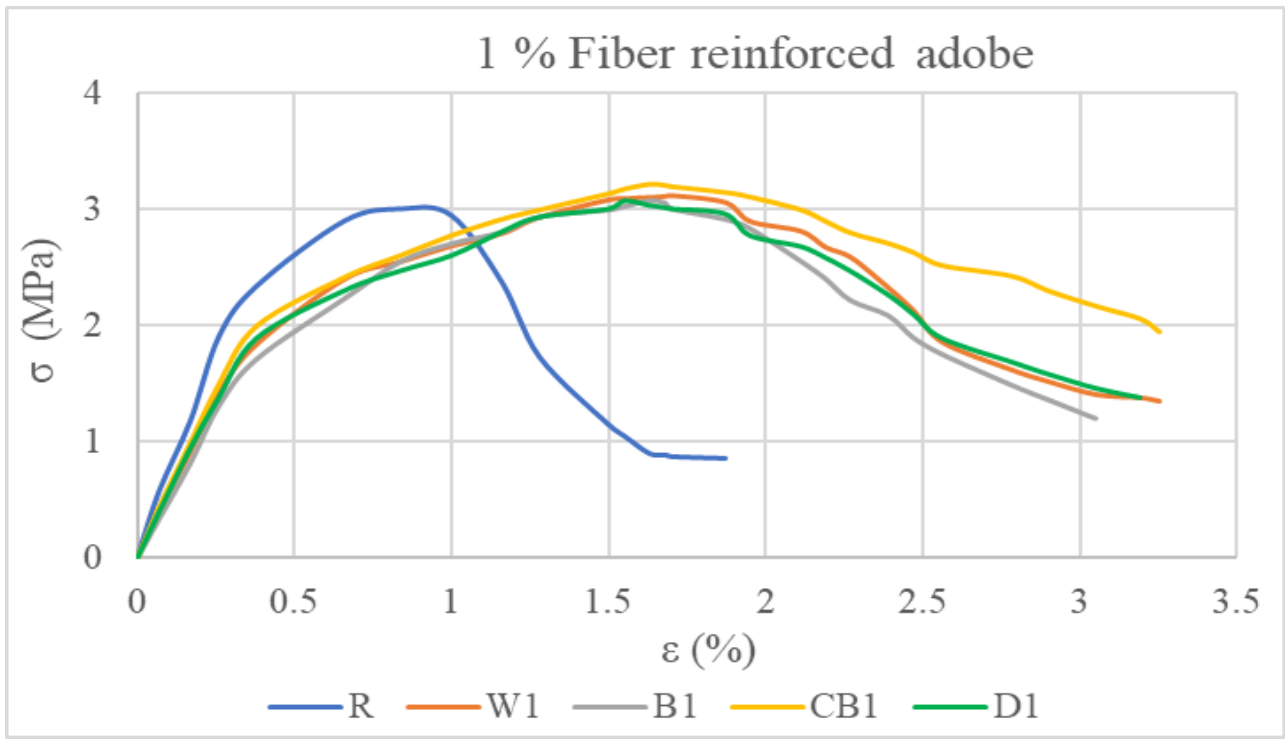

Figure 6. Stress-Strain curves of $1 \%$ fiber reinforced adobes 


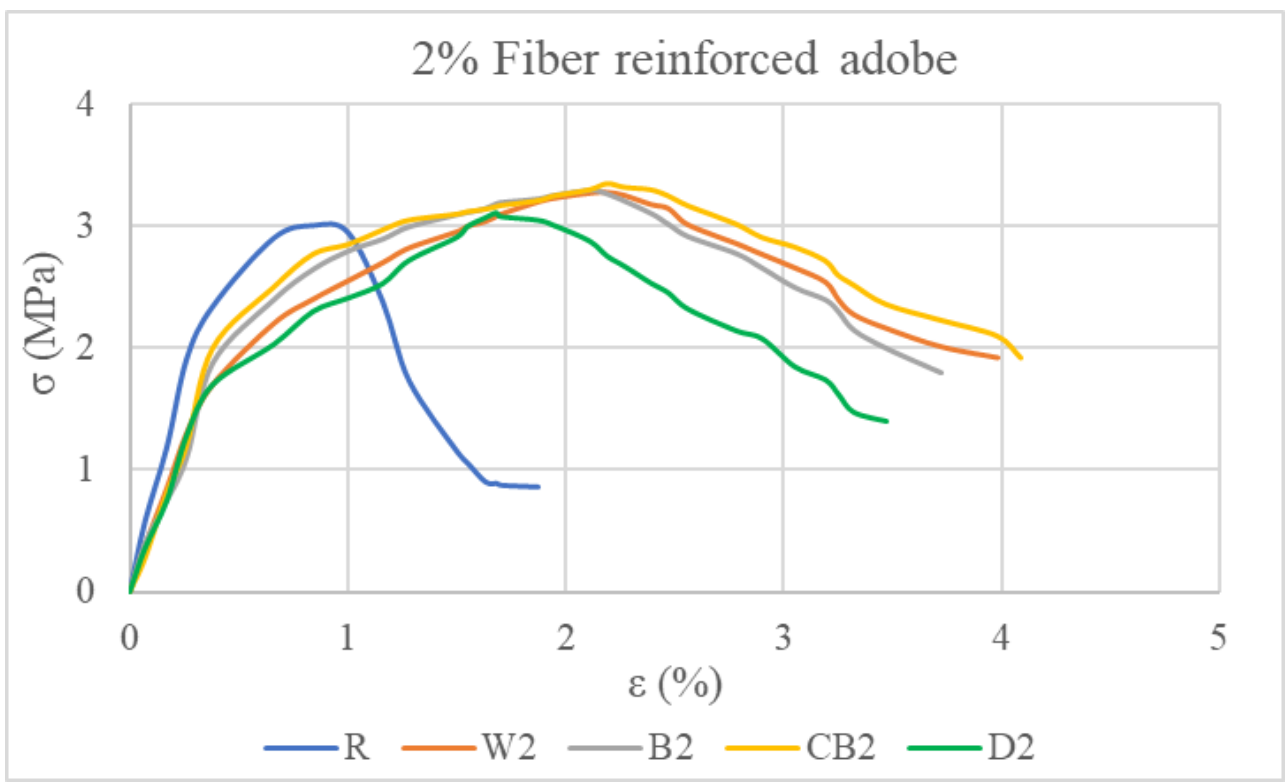

Figure 7. Stress-Strain curves of $2 \%$ fiber reinforced adobes

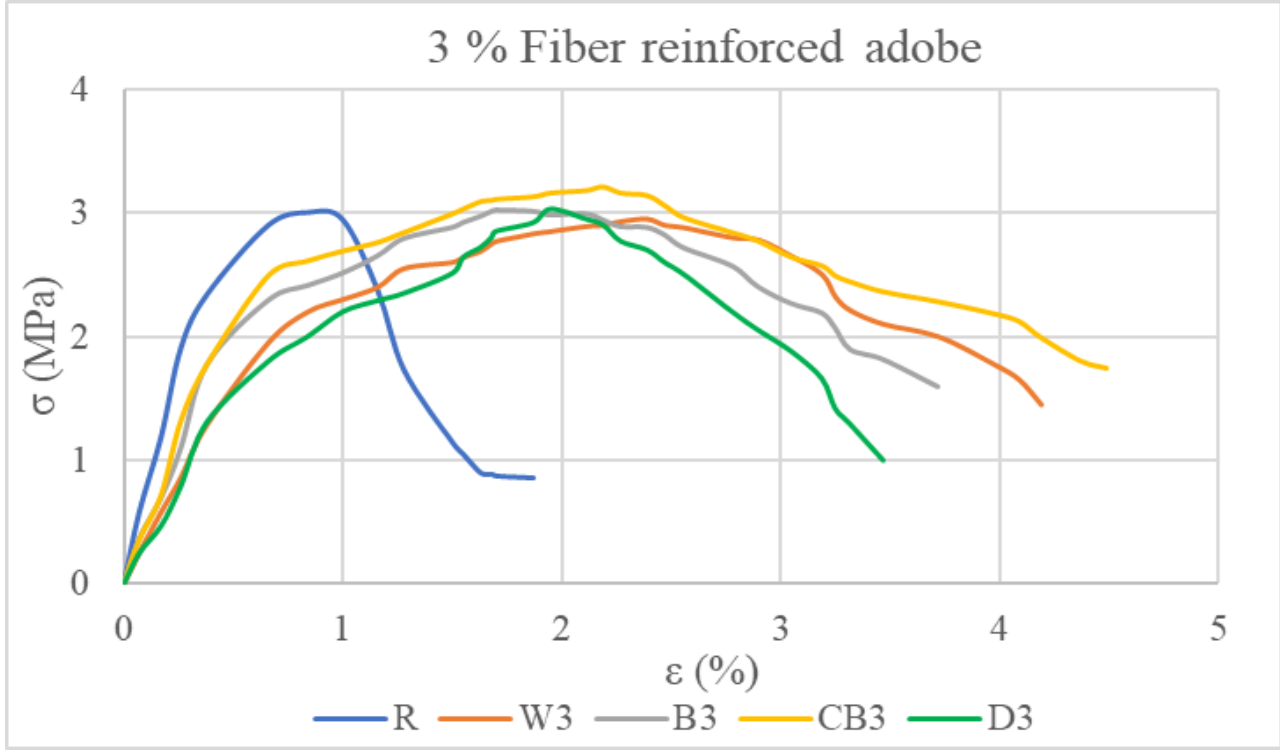

Figure 8. Stress-Strain curves of 3\% fiber reinforced adobes

The effect of fiber reinforcement gives greater compressive strength for all the fibers used in the study. The maximum resistance increases until reaching its peak for a fiber contribution of $2 \%$ for straw and $1.5 \%$ for sawdust, then the value of the resistance decreases beyond this contribution (Figure 9).

The maximum resistance increases until it reaches its peak for a fiber reinforcement of $2 \%$, and this is the optimal ratio in terms of resistance for all the fibers studied, beyond this ratio the resistance decreases. This reverse effect can be explained by the increase in the void index.

A similar result is found in the literature [18], the compressive strength increases and reaches a peak for a fiber ratio of $1.5 \%$ with a gain ranging from $10 \%$ to $20 \%$, then the resistance decreases.

\subsubsection{Elasticity and Ductility Analyses}

In the first part of the curve defining the elastic domain, the modulus of elasticity E, or Young's modulus, defined as the slope of the curve stress-strain, makes it possible to set up a correspondence between the variation of applied stress and the variation in deformation observed. Otherwise, to study the ductility of the material, an index I "adapted to the earth and earth fiber material was developed by [19]. The index I is defined as:

$$
\mathrm{I}=\varepsilon_{3} / \varepsilon_{2}
$$

where $\varepsilon_{3}$ refers to the axial strain when the stress drops to 0.85 of the maximum stress and $\varepsilon_{2}$ refers to the strain related to the maximum stress.

The modulus of elasticity $\mathrm{E}$ and the ductility index I 
values for the formulated adobes are summarized in Table 5.

As shown in the Table 5, the modulus of elasticity $\mathrm{E}$ decreases with fiber reinforcement, the results found in the literature are quite close and show E values ranging from $250 \mathrm{MPa}$ to $750 \mathrm{MPa}$ depending on the fiber content $[20,21]$. Otherwise, the reinforcement of the adobe increased the ductility index except for the D3 mixture. The improvement of the ductility is consistent with the finding of [19].

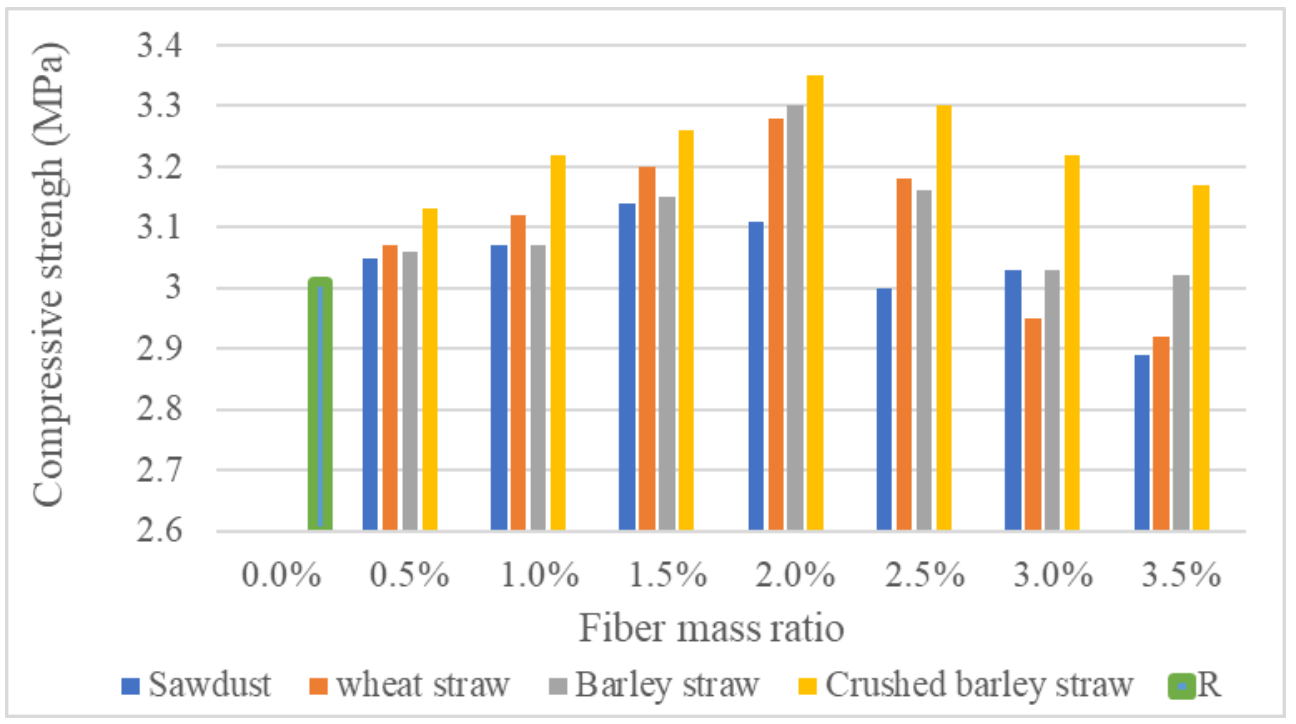

Figure 9. Different fibred adobes compressive strength

Table 5. Modulus of elasticity and ductility index for the different samples

\begin{tabular}{|c|c|c|c|c|c|c|c|c|c|c|c|c|c|}
\hline & & \multicolumn{4}{|c|}{$1 \%$ Fiber } & \multicolumn{4}{|c|}{$2 \%$ Fiber } & \multicolumn{4}{|c|}{$3 \%$ Fiber } \\
\hline Adobes & $\mathrm{R}$ & W1 & B1 & CB1 & D1 & W2 & B2 & CB2 & D2 & W3 & B3 & CB3 & D3 \\
\hline $\mathrm{E}(\mathrm{MPa})$ & 735 & 510 & 470 & 550 & 515 & 470 & 465 & 500 & 460 & 310 & 450 & 475 & 325 \\
\hline I & 1.28 & 1.30 & 1.39 & 1.46 & 1.40 & 1.32 & 1.31 & 1.39 & 1.34 & 1.33 & 1.31 & 1.30 & 1.28 \\
\hline
\end{tabular}

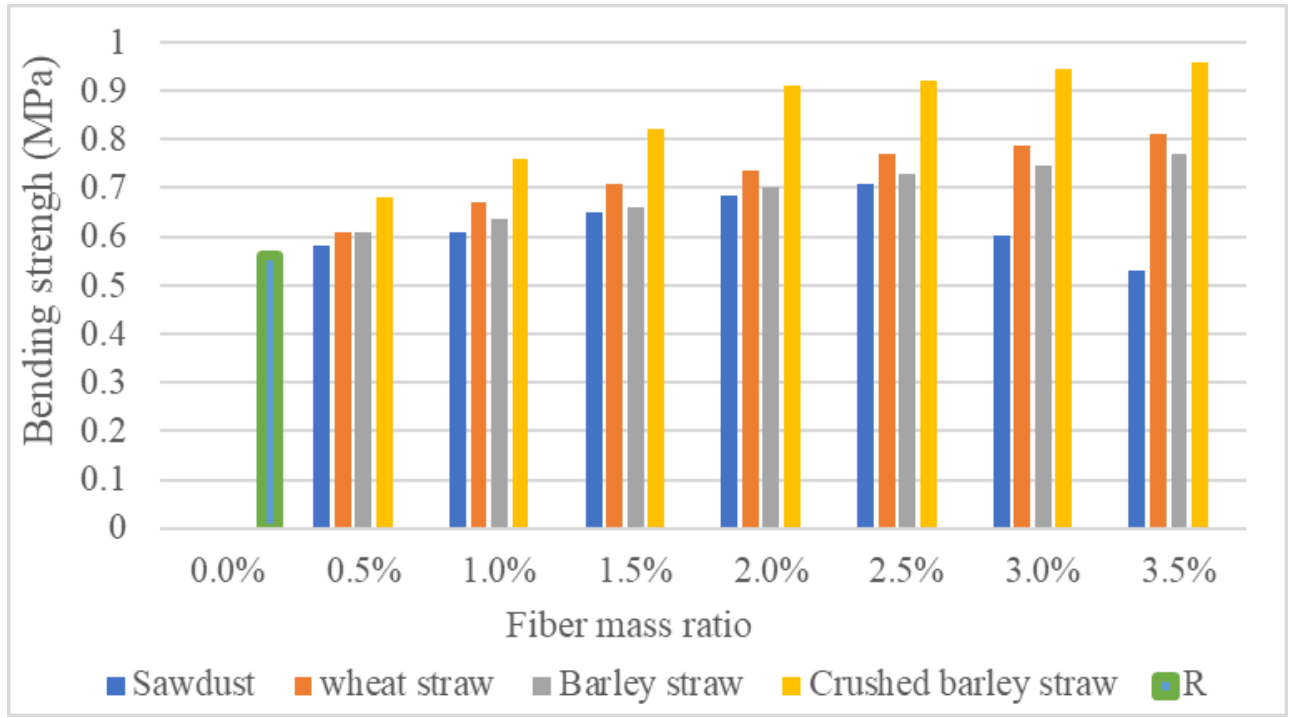

Figure 10. Different fibred adobes bending strength 


\subsubsection{Bending Test}

Figure 10 represents the evolution of bending strength (MPa) as a function of the mass ratio of fiber mass. The bending strength increased depending on the fiber content, except in the case of bricks reinforced with sawdust. This can be justified by the adhesion earth-sawdust of wood which is less important than the adhesion earth-straw. The gain in the bending strength reached $70 \%$ for an addition of $3.5 \%$ crushed barley straw. The evolution of the bending strength of the bricks reinforced with sawdust was different from that reinforced with a different straw. Indeed, those with sawdust experienced a peak at 2.5\% before deceasing, which can be explained by an adhesion earth-sawdust less than clay-straw adhesion. The crushing of barley straw allowed a substantial gain in strength (7\% at compression and $25 \%$ at bending).

The bricks reinforced by crushed barley straw achieved the greatest gain in strength, this can be explained by the higher bending strength for barley straw. However, this advantage is no longer visible if the straw is not crushed, a thing which can be explained by the porosity of the barley straw. When the latter is not crushed, it creates more vacuum at the level of the adobe, which naturally affects its mechanical performance. This has the effect of reducing the propagation of bending cracks and the number of cracks caused by shrinkage as well as the weight of earth structures [22-24].

\section{Conclusions}

The purpose of this research was first to study the earth used for traditional construction in the Moroccan south-east, then to determine an optimal reinforcement for the local adobe. Adobes with sawdust, wheat straw and barley straw with different contents were compared based on the mechanical properties. The study found that the locally available earth is classified as clayey sand and that its traditional reinforcement by straw is effective. Almost, the fibers increased the ductility of the adobe. Moreover, the reinforcement improved the compressive strength until $2 \%$ rate regardless the type of straw and $1.5 \%$ rate for sawdust.

The study showed a gain of nearly $12 \%$ in compressive strength and $62 \%$ in bending strength with the addition of $2 \%$ crushed barley straw.

An additional gain in bending strength is possible beyond $2 \%$ of fibers in reinforcement, but this is done at the expense of the compressive strength, so the optimal mass ratio of the fibers will be $2 \%$ for the different fibers studied.

The reinforcement with sawdust does not represent an advantage over that of straw. On the other hand, the study has shown that the crushing of barley straw has a very advantageous effect.

\section{REFERENCES}

[1] R. Anger, L. Fontaine. Bâtir en terre : du grain de sable à l'architecture, Editions Belin, Paris, 2009.

[2] M. T. Gil Piqueras, P. Rodríguez Navarro. Restoration of the Sidi Bou Guertif Marabout, El Khorbat, Morocco, Loggia, Arquitectura \& Restauración, No.32, 60-73.

[3] NF P 94-056, Particle size analysis by sieving, French standard, 1996.

[4] NF P 94-057, Particle size analysis by sedimentation, French standard, 1992.

[5] NF P94-051, Determination of Atterberg limits, French standard 1993.

[6] NF P94-068, Methylene blue adsorption capacity measurement, French standard, 1998.

[7] H. A. Barnes. A review of the slip (wall depletion) of polymer solutions, emulsions and particle suspensions in viscometers: its cause, character, and cure, Journal of non-Newtonian Fluids Mechanics, Vol.53, No.3, 221- 251.

[8] H. Houben, H. Guillaud. Traité de construction en terre. Editions Parenthèses, Marseille, 2006.

[9] T. A. Phung, M. Le Guern, M. Boutouil, H. Louahlia. Mechanical and thermal performance of cob materials. Academic Journal of Civil Engineering, Vol.35, No.2, 166-172.

[10] NF P18-560, Aggregates - Particle size distribution, French standards, 1990.

[11] LCP: Soil classification of « Ponts et chausées » laboratory, 1980.

[12] ASTM D2487-17e1 Standard Practice For Classification Of Soils For Engineering Purposes (Unified Soil Classification System), 2011.

[13] RPCT: the Moroccan earthquake-resistant earth construction regulation, 2011.

[14] Y. Zhang, A. E. Ghaly, B. Li. Physical properties of wheat straw varieties cultivated under different climatic and soil conditions in three continents, American Journal of Engineering and Applied Sciences, Vol.5, No.2, 98-106.

[15] N. 4297:1998, New Zealand Standard. Engineering Design of Earth Buildings. Standards New Zealand, Wellington, New Zealand, 1998.

[16] P. Walter. HB 195 the Australian earth building handbook, Standards Australia Press, Australia, 2002.

[17] New Mexico Earthen Building Code, 2015.

[18] M. Bouhicha, F. Aouissi, S. Kenai. Performance of composite soil reinforced with barley straw, Cement and Concrete Composites, Vol.27, No.5, 617-621.

[19] S. Imanzadeh, A. Jarno, A. Hibouche, A. Bouarar, S. Taibi. Ductility analysis of vegetal-fiber reinforced raw earth concrete by mixture design, Construction and Building Materials, Vol.239, 117829.

[20] R. Ilampas, V. G. Loizou, I. Ioannou. Effect of straw fiber reinforcement on the mechanical properties of adobe bricks, 
Sixth Biot Conference on Poromechanics, Paris, 1331-1338, 2017.

[21] L. Miccoli, U. Müller, P. Fontana. Mechanical behaviour of earthen materials: a comparison between earth block masonry, rammed earth and cob, Construction and Building Materials, Vol.61, 327-339.

[22] C. J. Miller, S. Rifai. Fiber reinforcement for waste containment soil liners. Journal of Environmental
Engineering, Vol.130, No.8, 891-895.

[23] C. S. Tang, B. Shi, L.Z. Zhao. Interfacial shear strength of fiber reinforced soil, Geotextiles and Geomembranes, Vol.28, No.1, 54-62.

[24] J. Khedari, P. Watsanasathaporn, J. Hirunlabh. Development of fibre-based soil-cement block with low thermal conductivity, Cement and Concrete Composites, Vol.27, No.1, 111-116. 